\title{
Development of an Instrumentation System for Evaluating the Tractive Performance of Walking Tractors
}

\author{
Showkat Rasool ${ }^{*}$, Hifjur Raheman and Ganesh Upadhyay
}

Department of Agricultural \& Food Engineering, Indian Institute of Technology, Kharagpur, West Bengal, 721302 India

*Corresponding author

\author{
A B S T R A C T
}

\begin{tabular}{|l|}
\hline K e y w o r d s \\
Walking tractor, \\
Instrumentation, \\
Proximity sensor, \\
Magnetic pickup, \\
Load cell, Fuel \\
consumption.
\end{tabular}

An instrumentation system to measure the performance of the walking tractor has been developed. The purpose of the system is to evaluate the performance of walking tractor by collecting necessary data for proper implement matching and farm management, and consequently improving the adaptability of these tractors. The parameters measured are engine speed, actual and theoretical speed, drawbar pull and fuel consumption. Major components of the system include magnetic pickup to measure engine speed, proximity sensors to measure tractor speeds, load cell transducer to measure drawbar pull and data logger to scan and record data from different transducers. A fuel measurement system is also installed on the system. Calibration curves were developed for the load cell and the fuel measurement system. Program was developed to convert sensor outputs into desired form. The speed measurement system was validated manually. The entire system was mounted on a walking tractor and field experiments were conducted to evaluate the performance of the developed instrumentation system by determining the draftability of the walking tractor. The tractor was loaded, and drawbar pull, slip and fuel consumption of the tractor were determined at different engine speeds and gears. It was concluded that the developed instrumentation system provides accurate and reliable results.

\section{Introduction}

Walking tractors are a well-accepted source of power for paddy cultivation in India and many other parts of the world. In view of scarcity of labors and need for timely completion of various farming operations, the demand for labour is increasing at a faster rate. However, walking tractors are still used only for limited number of operation because of their low draftability (Alvi and Pandya, 1968; Narang and Varshney, 1995, 2006; Sahay et al., 2009. To increase the versatility of walking tractors, proper matching implements should be designed and developed. For proper implement matching and field management of walking tractor, its tractive performance should be measured in different field conditions.

Parameters included in the traction performance of off-road vehicles on unprepared terrain are driving torque, ability to accelerate, drawbar pull, travel reduction (usually called slip), gross traction ratio, tractive efficiency, net traction ratio (sometimes called pull/weight ratio), motion resistance or rolling resistance (Goering, 
1989; Wong, 2001; Schreiber and Kutzbach, 2008; Zoz and Grisso, 2003).

Traditionally mechanical equipments have been used to measure the performance of tractors which were generally inconvenient to use. However, recent trend is to use electrical technology to measure the performance parameters of the tractors. Earlier systems included mechanical sensors, strip charts, oscillographs and manual recording of data (Cullum et al., 1989). Microcomputer and microelectronics based system utilizing onboard computer and signal conditioning hardware have been developed (Tompkins and Wilhelm, 1982). Several personal computer based systems have been developed to monitor the tractor performance (Carnegie et.al. 1983., Harter and Kaufman, 1979., Lin et.al, 1980., Wendte and Rozeboom, 1981)

There are different research methods of measurement of speed; rotational speed has been measured with magnetic frequency generator or optical frequency generator. Different techniques have also been used like Doppler radar effect (Thansandote et al., 1977; Thompkins et al., 1988) and electronic circuits using photo transducer (Lyne and Meiring, 1976) etc. for accurate measurement of slip. The development of inexpensive microwave Doppler radar units simplified the measurement of vehicle ground speed and such units are now offered as an option on most tractors.

The radar units transmit a known frequency of radiation towards a surface and receive reflections of the radiation from the surface. The Doppler frequency, the difference in frequency between the transmitted radiation and received radiation, is proportional to speed. The problem with this type of measuring devices is that they are ineffective in vegetated fields. Raheman and Jha (2007) developed a microcontroller based slip measurement system which comprised of proximity sensors and display unit. The performance of the developed system was evaluated on tarmacadam surface and in field conditions.

Drawbar pull is conventionally measured by load cell. Besselink dynamometer (Besselink, 2004) consists of S-type load cell to measure dynamic force along the longitudinal axis. Ahmad et al., (2011) presented the development of a test rig for measuring motion resistance of towed narrow wheels. The towing force which is equal to the motion resistance is measured by a Basic Force Gauge (BFG) installed on the test rig.

Fuel consumption can be measured by several methods ranging from expensive fuel flow meters to simple inexpensive indicating-type and weighing-type devices. Fuel flow meters used to measure fuel consumption of a tractor give instantaneous fuel consumption with high accuracy and precision. Two fuel flow sensors are used in differential mode; one fitted between the fuel filter and the injector pump and the other on the returning line from the injector to the tank. However, such flow sensors are expensive and may not work properly in walking tractors due to lower fuel consumption as compared to tractors.

The objective of the present study was to develop a flexible instrumentation system to measure and record tractive performance indicators of walking tractors. The parameters measured are forward speed, drive wheel speed, drawbar pull and fuel consumption.

\section{Materials and Methods}

Instrumentation system has been developed to determine engine speed, travel speed, drawbar pull and fuel consumption. A data analysis program was also developed on MATLAB platform to analyze the collected data. 
Measurement of engine speed, vehicle speed and slip of vehicle

Magnetic pickup sensor was used to measure the engine speed. A steel projection attached to the flywheel of the walking tractor acts as an obstruction which disturbs the magnetic field of the magnetic sensor probe and induces voltage which can then be used to measure the speed. The voltage generated by the magnetic pickup sensor was converted into engine rpm.

Two proximity sensors were used to measure the theoretical velocity $\left(V_{t}\right)$ and the actual velocity $\left(V_{a}\right)$ of the walking tractor. The theoretical velocity was measured by a device consisting of a proximity sensor and a ring with 9 spikes fitted on the drive axle (Fig. 1). The proximity sensor was placed in front of the projections and it produced a pulse whenever a projection passed the sensor. The actual speed of operation was measured by means of an extra wheel attached to the tractor body near the drive axle (Fig. 2). The wheel was spring loaded so that it always remained in contact with the ground. A mild steel ring with projections was fixed to the extra wheel and a proximity sensor was installed in front of it. Whenever a projection passed the proximity sensor, a pulse was generated that was recorded by the data acquisition system. The output of the proximity sensors in the form of pulses was analyzed in the computer program developed using MATLAB (discussed in subsequent sections).

Slip of the vehicle, $s$ was calculated using Eq. 1 as given below:

$s=\frac{V_{a}-V_{t}}{V_{t}} \times 100$

To validate the slip measuring system, the vehicle slip was also measured from wheel rotation. Wheel surface was marked and vehicle was allowed to move for ten revolutions with and without load. The distance covered in ten revolutions with and without loading the tractor was used to calculate the slip of the vehicle using Eq. 2.

$S=\frac{d_{N l}-d_{w l}}{d_{N l}}$

Where, $d_{N 1}$ and $d_{\mathrm{wl}}$ represent the distances covered in ten revolutions of the wheel under no load and loaded conditions, respectively. A merely 5 per cent variation was observed between the slip calculated using proximity sensors and that computed from the wheel revolutions under no load and loaded conditions, which was considered acceptable.

\section{Measurement of drawbar pull}

To measure drawbar pull, a 2 Ton S-type load cell from local supplier was mounted between the test tractor and a towed tractor (Fig. 3). The load cell has a nominal sensitivity of $2 \mathrm{mV} / \mathrm{V}$, composition error of \pm 0.03 and excitation voltage range of $9-12 \mathrm{~V}$ (DC). An L-shaped bracket made of $\mathrm{C}$ channel was mounted on the rear of the walking tractor with one side bolted to the implement frame and on the other side, a groove was cut out for attaching and adjusting the load cell so as to ensure that the hitch line is kept parallel to ground surface.

\section{Data logging system}

Data from the different sensors and transducers were recorded using the data logging system. In operation, excitation voltage is supplied by the data logger to the transducers which in turn produce output signals that are recorded by the data logger. Figure 4 is the block diagram of the instrumentation system to record output from different sensors. The data acquisition system 
consists of HBM QuantumX data logger and an onboard PC (Fig. 5). The power supply to the data logger and the $\mathrm{PC}$ is provided by a 12 $\mathrm{V}$ battery through DC to AC power inverter. The QuantumX data logger has 8 channels for acquisition of data from different sensors. The transducers are connected to the data logger through commercially available 15 pin 3 row D-type connectors. The data logger is connected to the PC through Ethernet. The data from the data logger is displayed on personal computer through Catman Easy software package and is stored in it. The software package helps in selecting a particular channel for data recording, configuring the transducer, adjusting the sampling frequency and measurement range, and carrying out tarring. The software user interface consists of text boxes provided on the front panel that display options for its operation. After configuration of all the transducers, the settings can be saved and can also be recalled later. The data recording can be started by clicking on a start box provided on the panel. The graphs update in real time during each run. The data can then be saved in a particular format for further processing with spreadsheets or other soft wares. Figure 6 shows the instrumented walking tractor.

\section{Measurement of fuel consumption}

The fuel consumption measuring system consists of an auxiliary fuel tank, a measuring scale, valves and pipes. The block diagram of the fuel measuring system is shown in figure 7. A15 cm scale was fitted to the auxiliary fuel tank for measurement of fuel consumption. Calibration of the system was carried out by keeping the tank in horizontal position and for known volume of diesel added to the tank, the corresponding rise of fuel in auxiliary fuel tank was noted with the help of scale placed close to it. Calibration curve was obtained by repeating the procedure for several known volumes of fuel added to the tank.

\section{Program for data analysis}

Program was developed in MATLAB platform to analyze the data collected from the data acquisition system. The MATLAB program calls the data file saved in personal computer in excel format. Each row in an excel file contains data of a particular sensor. The screen shot of output excel file containing data of different sensors is shown in figure 8 . Each row is analyzed by the MATLAB program and plotted for evaluation. The magnetic pickup data is in the form of pulses with each pulse representing one revolution. Number of pulses per unit time was calculated by MATLAB program and engine revolutions per unit time was displayed as output. The MATLAB program counted the number of pulses from two proximity sensors in a given test run and converted it into respective speed values using Eq. 3 (a) and 3 (b) for theoretical and actual velocity, respectively.

$V_{t}=\frac{2 \pi r_{t} P_{t}}{t}$
$V_{a}=\frac{2 \pi r_{a} P_{a}}{t}$

Where $r_{t}$ is the rolling radius of the drive wheel, $P_{t}$ is the number of pulses generated in time $t$ per each projection in the ring fixed on the drive shaft (which gives the number of revolutions of the ring in time $t$ ), $P_{a}$ is the number of pulses generated in time $t$ per each projection in the ring fixed on the extra wheel and $r_{a}$ is the rolling radius of the extra wheel

The data of draft recorded by load sensor is found to vary from a mean point with occasional peaks due to ground disturbances along the travel distance. The MATLAB program removes any unwanted peak values and also removes the first and last $10 \%$ of the data to allow a transducer to achieve desired 
value and any mismatch between stopping of the data acquisition at the end. The MATLAB program then calculates the average of the draft along the test run. The data were then analyzed using statistical and graphical analysis.

\section{Results and Discussions}

\section{Calibration of load cell and fuel} measurement system

Load cell transducer for measuring the drawbar pull was calibrated with a certified load cell with digital display using mechanical floor crane. Transducer was hanged between digital load cell and pulley of the crane. The transducer was gradually loaded with ratchet pinion of the loading crane and output of the transducer corresponding to the crane scale output was recorded. The calibration curve is shown in figure 9 .

The fuel measuring system was also calibrated by keeping the tractor on level ground. Known value of diesel was added in auxiliary tank and corresponding rise in the scale was noted down. Same procedure was repeated for several volumes and calibration curve was drawn as shown in figure 10.

\section{System performance}

To evaluate the performance of the developed instrumentation system, experiments were conducted in field conditions by evaluating the traction characteristics of the walking tractor. Before the commencement of the test, it was ensured that the test tractor and the towed tractor are placed on level ground in both lateral and longitudinal directions and the line of pull is horizontal to the ground surface (Fig. 11). All the instruments were calibrated and checked for proper functioning. The sampling frequency of the data logger was set at 150 samples per second. The drawbar pull was applied by adjusting the speeds of the test tractor and the load tractor. The travel speed of load tractor was kept less than that of the test tractor and was steadily adjusted to obtain the desired pull. The pull was observed in the PC. Data recording was triggered by clicking on start box. Each test was carried out on a length span of about 25 $\mathrm{m}$. Tests were conducted for different pull values $(0-2.5 \mathrm{kN})$. Over the test span, the coefficient of variation of drawbar pull was less than $15 \%$.

\section{Drawbar pull measurement}

Figure 12 shows the variation of drawbar pull with travel distance at various loading values. The general shape of the curves of drawbar pullversus travelling distance can be identified by three phases, viz. starting of the vehicle characterized by initiation of draft, sudden increase of draft characterized by peak of force and then stabilizing force when the tractor reached a constant speed. The drawbar pull value was calculated from the average of the forces in a stable range of the curve.

\section{Velocity measurement and slip validation}

The proximity switches installed on drive wheel and extra wheel generated pulses as the spikes passed through the proximity switch. Proximity sensor installed on drive wheel gives theoretical speed and sensor on extra wheel gives actual speed. Figure 13 shows the variation of pulses from proximity sensor at different speed values. As the speed decreases, the distance between the consecutive pulses increases and vice versa.

The output of the proximity switches is converted into respective speed values, i.e. actual speed and theoretical speed and then slip is calculated. 


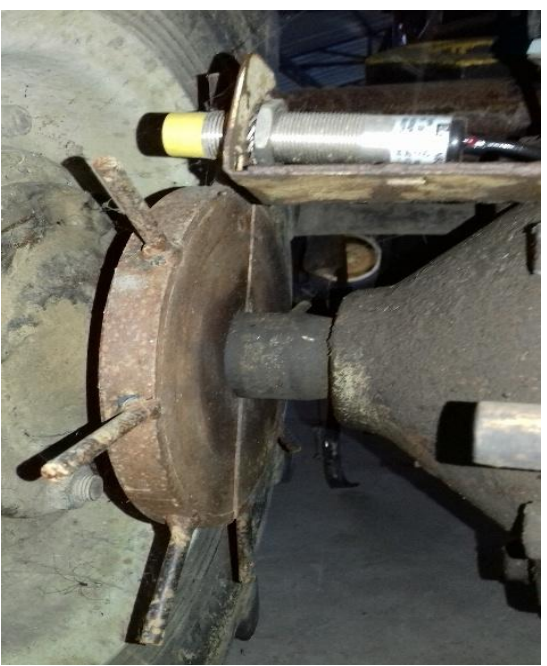

Fig.1 Spiked ring and proximity sensor on drive wheel to measure theoretical speed

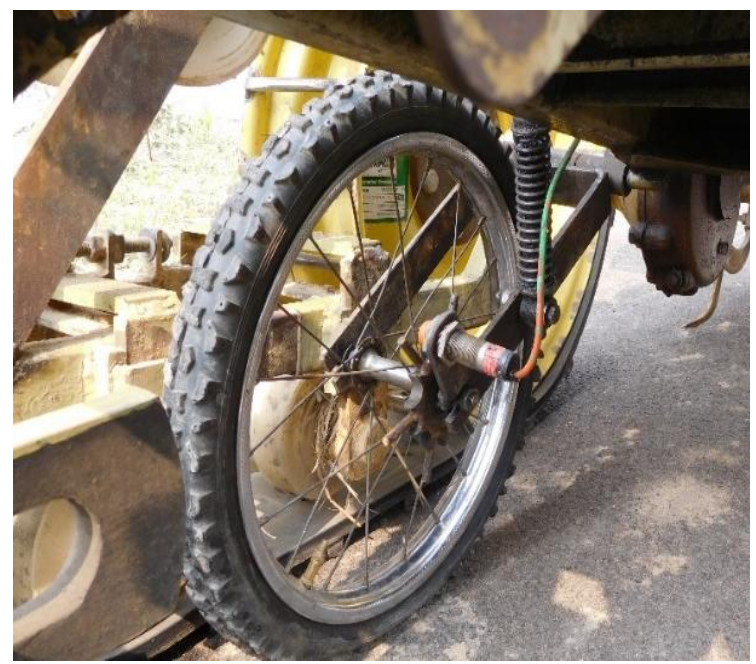

Fig.2 A spring loaded extra wheel to measure actual vehicle speed

Fig.3 Load cell hitched between the test tractor and a towed tractor (not in picture)

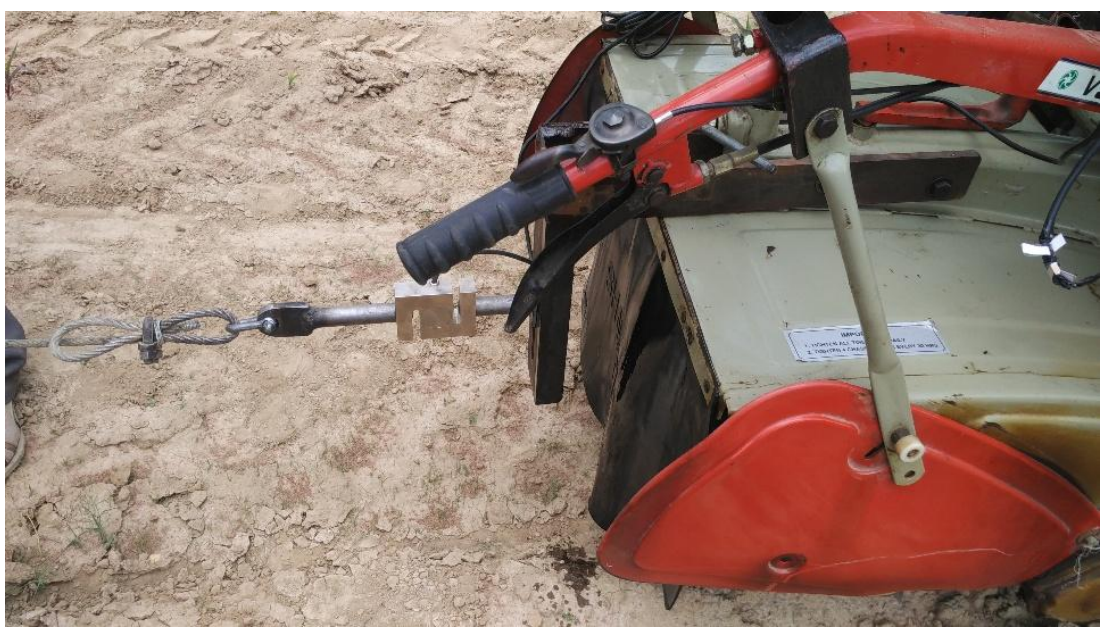

Fig.4 The data logging system

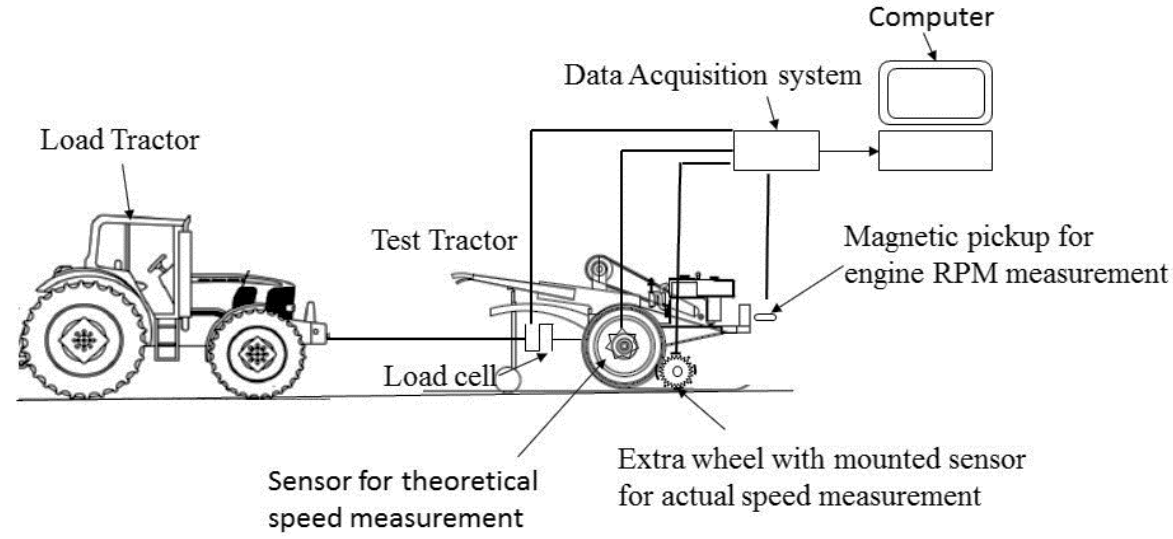


Fig.5 HBM QuantumX data logger and an onboard PC

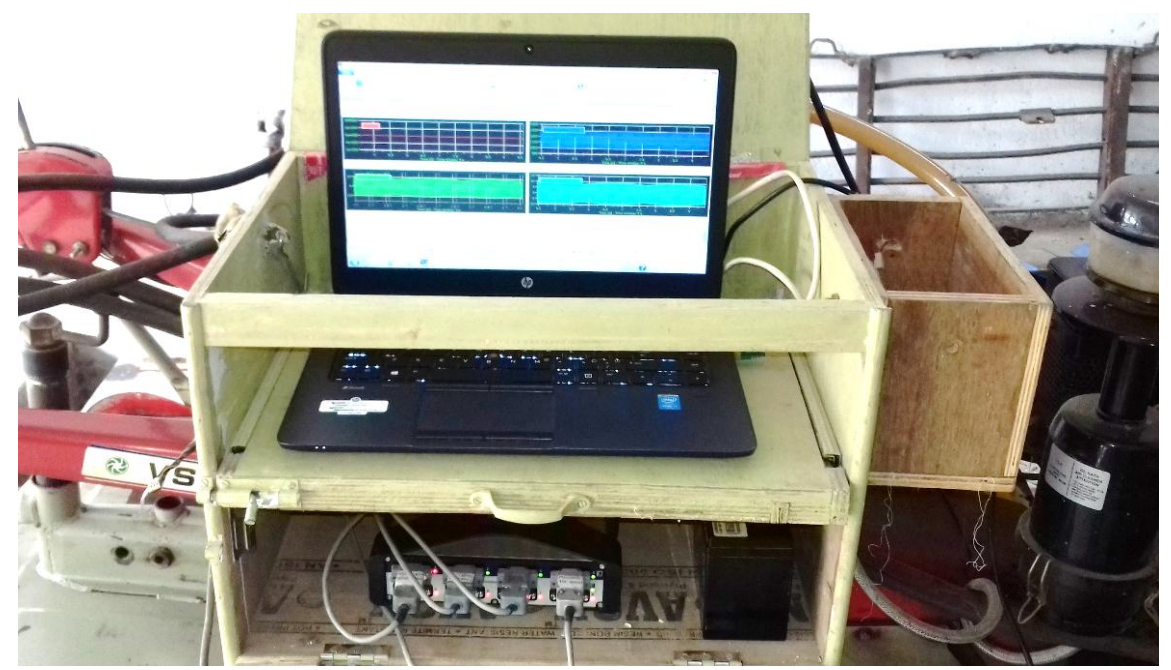

Fig.6 Instrumented walking tractor

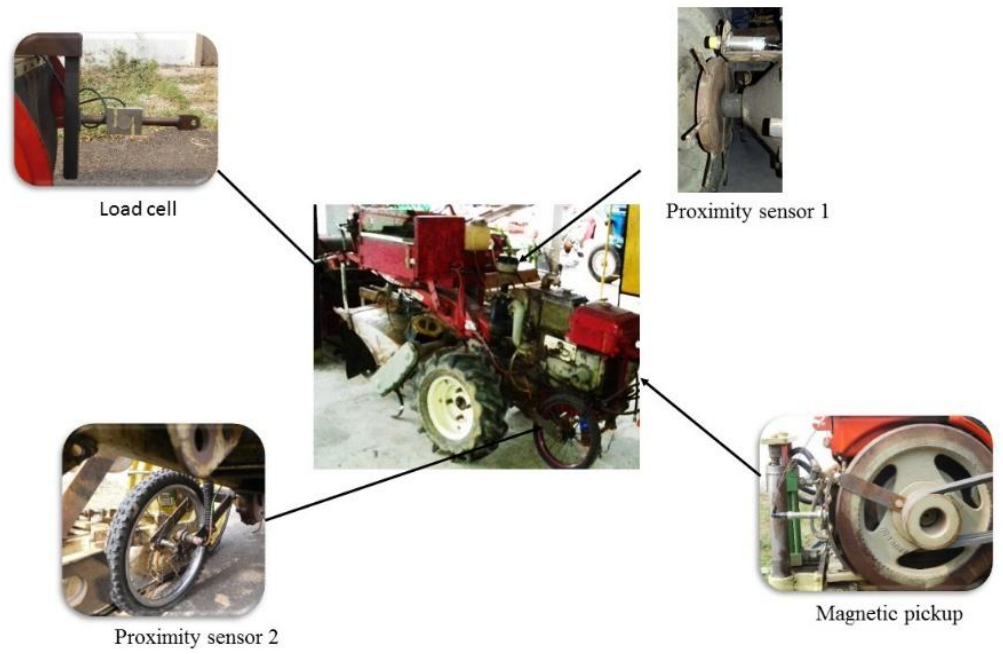

Fig.7 Setup to measure fuel consumption

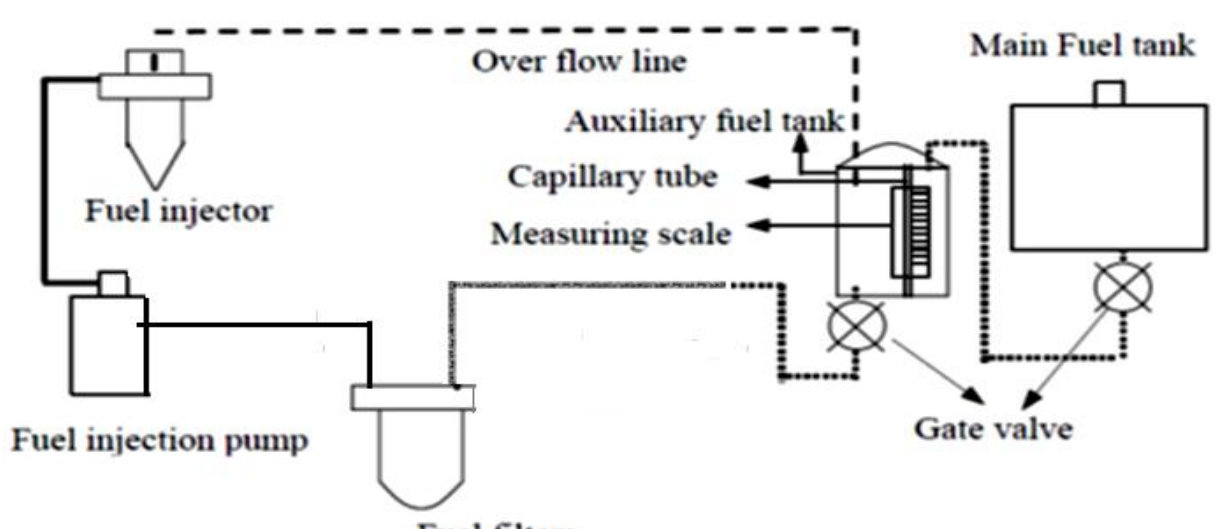

Fuel filters 
Fig.8 Screen shot of the data from different transducers of instrumentation sytem

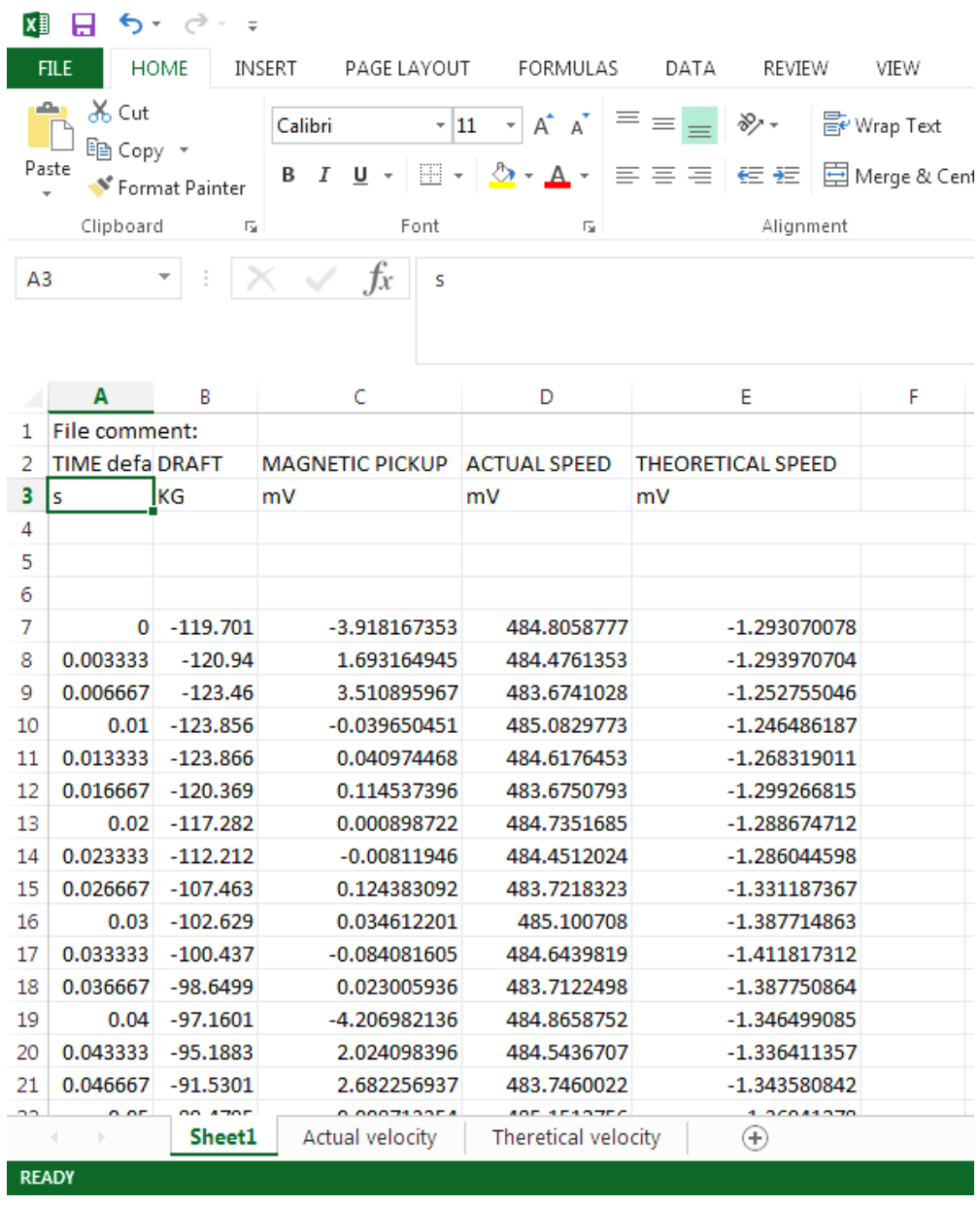

Fig.9 Calibration of load cell for drawbar pull measurement

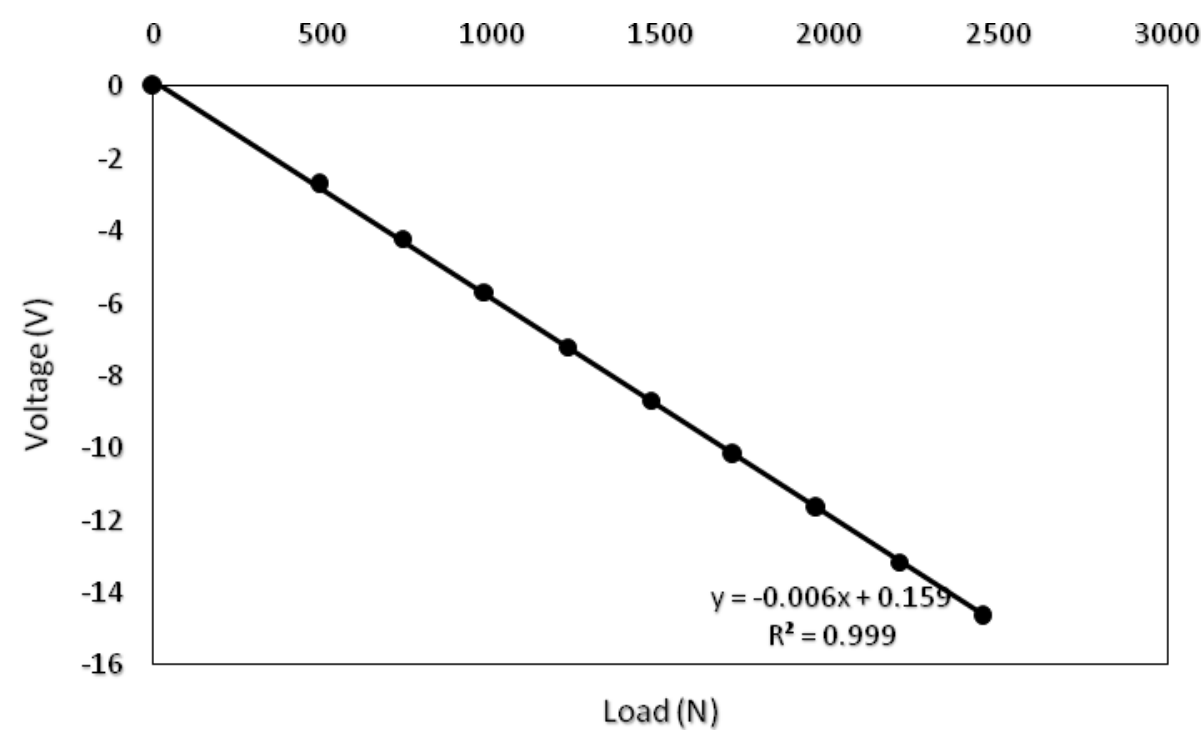


Fig.10 Calibration of fuel measurement system

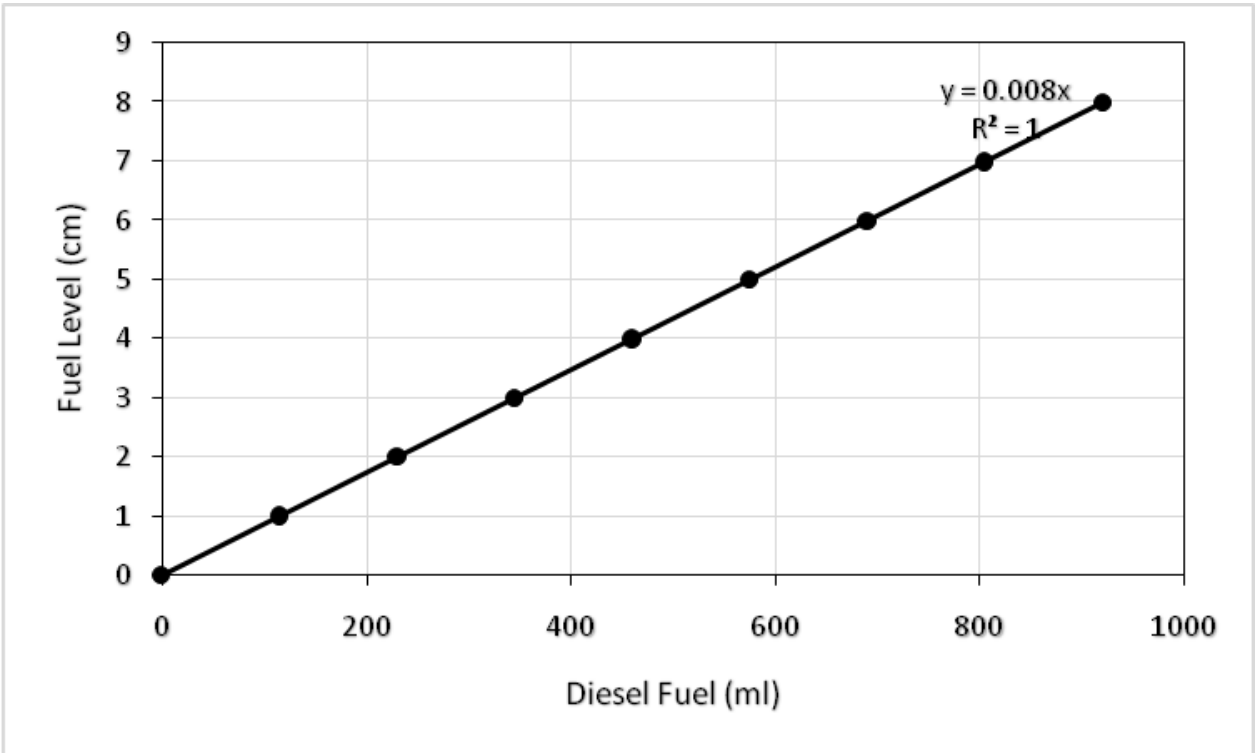

Fig.11 Arrangement for measurement of system performance

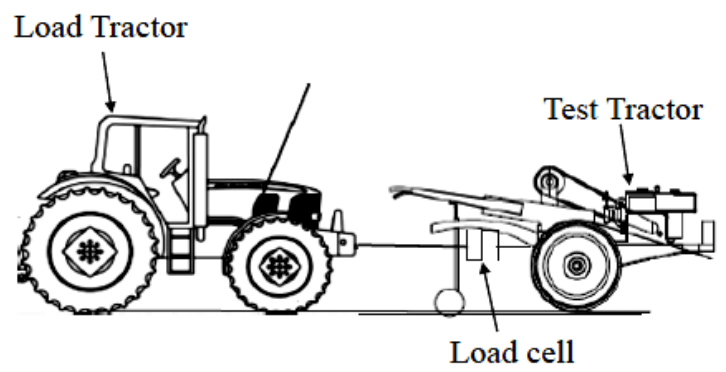

Fig.12 Variation of drawbar pull along the test span

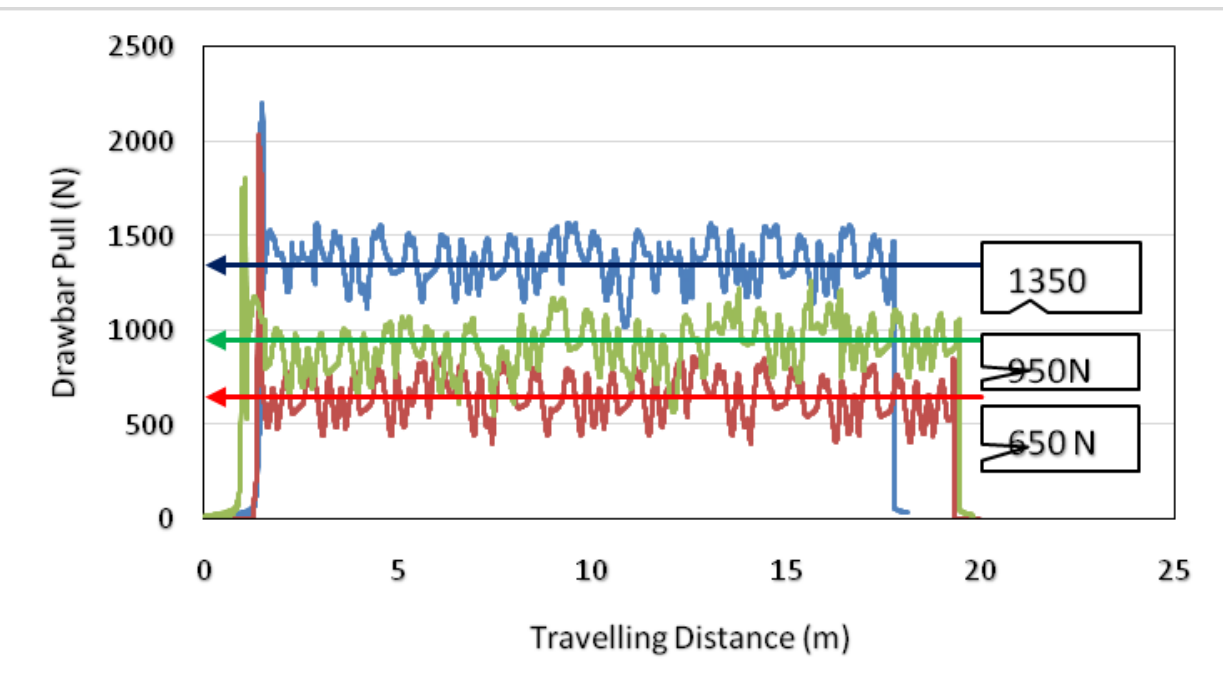


Fig.13 Output of proximity sensors at different speed values
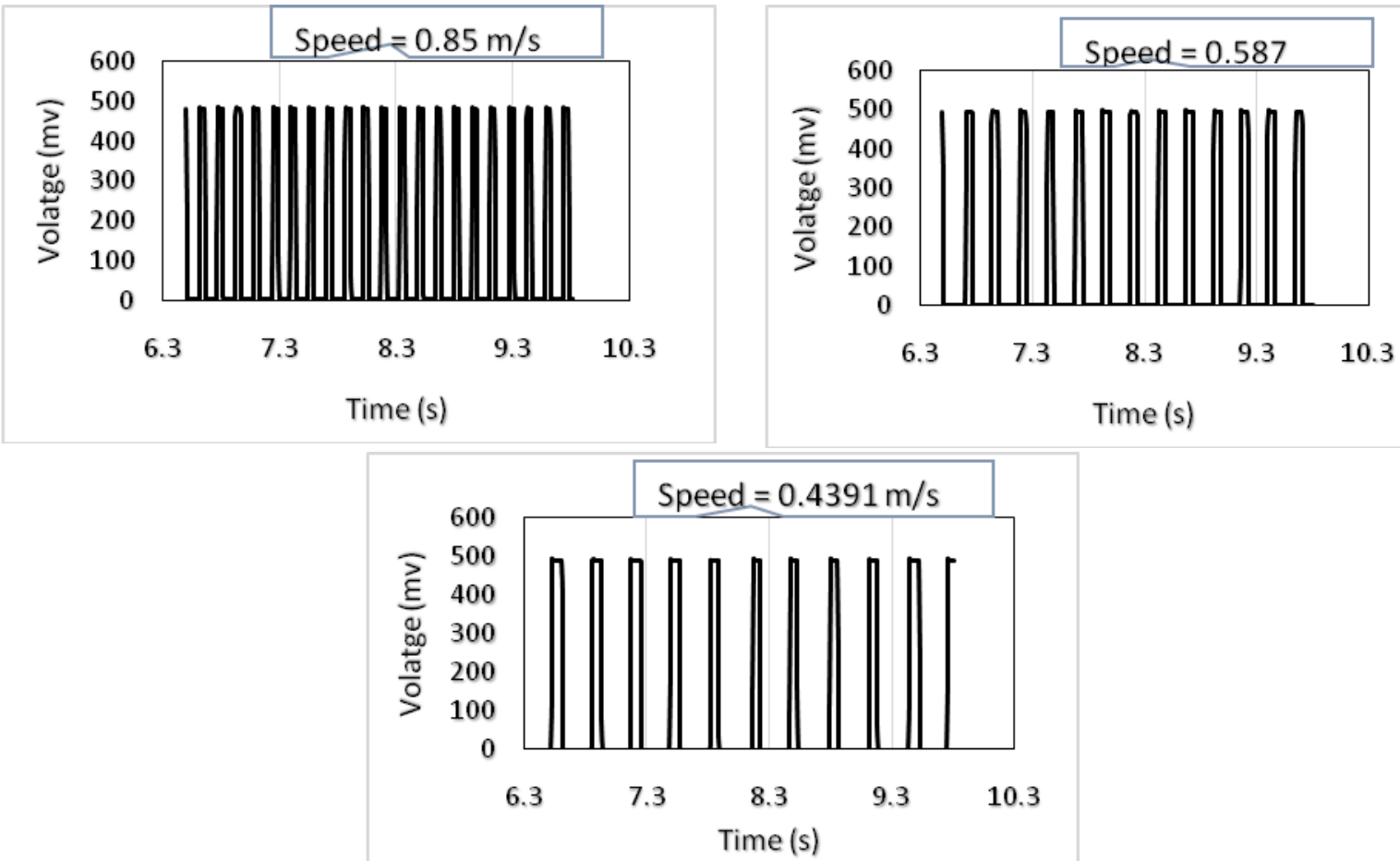

Fig.14 Validation of slip measurement system

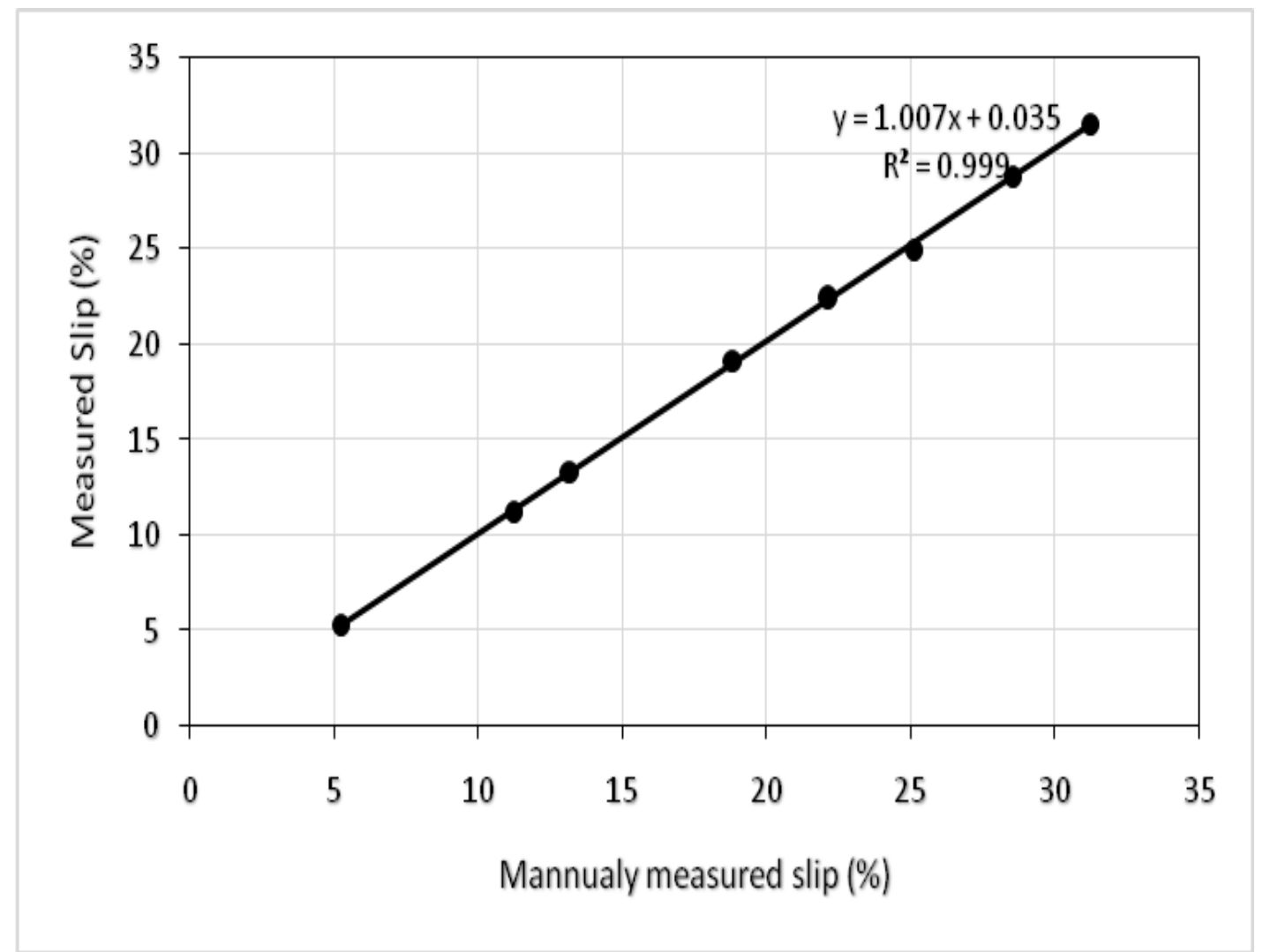


Table.1 Field performance of walking tractor as recorded by the developed Instrumentation system

\begin{tabular}{|l|l|l|l|l|l|}
\hline Gear Used & Engine speed & Slip & Actual Speed & Draft & $\begin{array}{l}\text { Fuel consumption } \\
(1 / \mathrm{h})\end{array}$ \\
\hline \multirow{4}{*}{ L2 } & 1489 & 8.34 & 0.385 & 596.56 & 0.611 \\
\cline { 2 - 6 } & 1505 & 17.98 & 0.338 & 1125.65 & 0.642 \\
\cline { 2 - 6 } & 1478 & 22.51 & 0.298 & 1278.75 & 0.691 \\
\hline \multirow{4}{*}{ 2 } & 1985 & 0.1052 & 0.515 & 750.365 & 0.751 \\
\cline { 2 - 6 } & 2008 & 0.1571 & 0.484 & 1101.250 & 0.782 \\
\cline { 2 - 6 } & 2016 & 0.2063 & 0.461 & 1236.360 & 0.801 \\
\hline \multirow{4}{*}{ 33 } & 1526 & 0.1295 & 0.562 & 859.505 & 0.652 \\
\cline { 2 - 6 } & 1510 & 0.1925 & 0.509 & 1126.369 & 0.692 \\
\cline { 2 - 6 } & 1518 & 0.2254 & 0.483 & 1300.256 & 0.721 \\
\hline \multirow{4}{*}{ L3 } & 2022 & 0.1125 & 0.747 & 905.350 & 0.911 \\
\cline { 2 - 6 } & 1955 & 0.1922 & 0.682 & 1290.250 & 0.931 \\
\cline { 2 - 6 } & 2011 & 0.2579 & 0.639 & 1335.256 & 0.951 \\
\hline
\end{tabular}

The slip calculated above was validated with the slip measured manually. The slip of the tractor was varied by loading the test tractor with load tractor. Figure 14 shows the validation of slip measurement system.

The data obtained from the different transducers were saved by data logger in excel format, which was further put to processing in MATLAB to obtain desired processed output. The parameters obtained are engine speed, slip, actual speed and draft. The fuel consumption readings were read from fuel measuring system. The performance parameters are shown in Table 1. It is observed that drawbar pull increases with increase in slip. It has also been observed that fuel consumption also increases with increase in drawbar pull. The detailed experimental analysis is beyond the scope of this article.

To evaluate the performance of walking tractors, an instrumentation system has been developed by installing different transducers to measure different performance parameters. Magnetic pickup was installed to measure the engine speed, proximity sensors were used to measure the actual and theoretical speed to be subsequently used for slip measurement and drawbar pull was measured by load cell. HBM data logger was used to scan data from different sensors and to display and record it in personal computer. MATLAB program was used to further process the data for statistical and graphical interpretation. Fuel measuring system was also developed to measure the fuel consumption of the system. The system was tested in a field and was found to provide accurate and reasonable results. The developed instrumentation system is a reliable system for evaluation of walking tractors.

\section{References}

Ahmad, D., Shamsuddin, S., Fashina, A.B. and Akande, F.B., 2012. Development of a tractor-pulled motion resistance test rig for traction studies on towed narrow wheels. International Journal of Agricultural and Biological Engineering, 4(4), pp.21-27.

Alvi S.A.A, Pandya A.C. 1968. Testing of walking tractor. The Harvester, Indian 
Institute of Technology, Kharagpur, (W.B.) India 10(1):59

Besselink, B.C., 2004. Development of a vehicle to study the tractive performance of integrated steering-drive systems. Journal of Terramechanics, 41(4), pp.187-198.

Carnegie, E.J., Grinnell, R.R. and Richardson, N.A., 1983. Personal computer for measuring tractor performance. Microfiche collection.

Goering, C.E., 1992. Engine and tractor power (No. Ed. 3). American Society of Agricultural Engineers (ASAE).

Graham, W.D., Cullum, R.E. and Gaultney, L.D., 1987. Energy requirements for conservation tillage in Alaska (No. 871003). ASAE Paper.

Harter, D.D. and Kaufman, K.R., 1979. Microprocessor based data acquisition system for tractor tillage measurements. Paper-American Society of Agricultural Engineers (USA). no. 79-5026.

Lin, T.W., 1980. microprocessor based data acquisition system to measure performance of a small four-wheel drive tractor.

Lyne, P.W. and Meiring, P., 1977. A wheel slip meter for traction studies. Transactions of the ASAE, 20(2), pp.238-0242.

Narang S Varshney A C., 1995. Evaluation of a $6.71 \mathrm{~kW}$ power tiller for draft and drawbar power on tar roads. Journal of Terramechanics 32(2): 91-97.

Narang, S. and Varshney, A.C., 1995. Evaluation of a $6.71 \mathrm{~kW}$ power tiller for draft and drawbar power on tar roads. Journal of terramechanics, 32(2), pp.9197.

\section{How to cite this article:}

Showkat Rasool, Hifjur Raheman and Ganesh Upadhyay. 2017. Development of an Instrumentation System for Evaluating the Tractive Performance of Walking Tractors. Int.J.Curr.Microbiol.App.Sci. 6(10): 759-770. doi: https://doi.org/10.20546/ijcmas.2017.610.092
Raheman, H. and Jha, S.K., 2007. Wheel slip measurement in 2WD tractor. Journal of terramechanics, 44(1), pp.89-94.

Sahay, C.S., Thomas, E.V. and Satapathy, K.K., 2009. Performance evaluation of a novel power-tiller-operated oscillatory tillage implement for dry land tillage. Biosystems engineering, 102(4), pp.385-391.

Schreiber, M. and Kutzbach, H.D., 2008. Influence of soil and tire parameters on traction. Research in Agricultural Engineering, 54(2), pp.43-49.

Thansandote, A., Stuchly, S.S., Mladek, J., Townsend, J.S. and Shlosser, H., 1977. A new slip monitor for traction equipment. Transactions of the ASAE, 20(5), pp.8510856.

Tompkins, F.D. and Wilhelm, L.R., 1982. Microcomputer-based, tractor data acquisition system. Transactions of the ASAE, 25(6), pp.1540-1543.

Tompkins, F.D., Hart, W.E., Freeland, R.S., Wilkerson, J.B. and Wilhelm, L.R., 1988. Comparison of tractor ground speed measurement techniques. Transactions of the ASAE, 31(2), pp.369-0374.

Wendte, R.W. and Rozeboom, H., 1981. Data acquisition for tillage energy evaluation. Paper-American Society of Agricultural Engineers (Microfiche collection) (USA). no. fiche no. 81-1045.

Wong, J.Y., 2008. Theory of ground vehicles. John Wiley \& Sons.

Zoz, F.M. and Grisso, R.D., 2003. Traction and Tractor Performance, ASAE Distinguished Lecture Series\# 27, ASAE Publication Number 913C0403. In: Agricultural Equipment Technology Conference held at Louisville, Kentucky, USA between February (pp. 9-11). 